\title{
Research on the bending moment-curvature relationship of wide notch concrete beam strengthened with EBR CFRP plate
}

\author{
Zhenhua Ren ${ }^{1,2, a}$, Xiantao Zeng ${ }^{2}$ and Wenjun Qu ${ }^{1,3}$ \\ ${ }^{1}$ College of Civil Engineering of Tongji University, Shanghai, 200092, China \\ ${ }^{2}$ School of Building Engineering of Hunan Institute of Engineering, Xiangtan 411104, China \\ ${ }^{3}$ State Key Laboratory of Disaster Reduction in Civil Engineering, Tongji University, Shanghai 200092, China
}

\begin{abstract}
Based on the hypothesis of neglecting tensile strength of concrete when concrete beam is bended, the simple bending concrete cover of four-point bending concrete beam is cut, thus forming a " $\pi$-shaped" notch on the side elevation of the beam. Such beam is called a wide notch concrete beam, which is a new abnormal concrete beam used to study the characteristics of the CRFP (Carbon fiber reinforced plastic plate )plate-concrete interface. With consideration of some theoretical hypotheses, computational analysis, and static load test of 4 common concrete beams with externally bonded reinforcement of CFRP plate (EBR CFRP), 4 concrete beams with wide notch and 3 simple concrete beams (control group), this study investigated the calculation formula for the bending moment-curvature of concrete beam with EBR CFRP and wide notch under different loading phases. The theoretical values of cracking load, yield load, ultimate load and corresponding curvature of the reinforced concrete beam were then calculated. These theoretical values agree well with the test results.
\end{abstract}

Keywords: externally bonded reinforcement; carbon fiber reinforced plastic plate; seismic strengthening; wide-notch concrete beam; moment-curvature.

\section{Introduction}

Externally bonded reinforcement of CFRP plate (EBR CFRP) is used for concrete members that fail to adopt embedding CFRP reinforcement. However, numerous experimental studies reported debonding failure of CFRP on concrete members using EBR CFRP[1-5]. Such debonding failure is identified as brittle failure without evident mechanical signs before failure but with low stress-strain in the CFRP bar at failure. This failure not only causes material waste, but also significantly reduces the security of the reinforced system[6-9]. The bonding properties of CFRP plate-concrete interface is the key factor influenc-ing, concrete beams using EBR CFRP. Based on the hypothesis of neglecting tensile strength of con-crete when concrete beam is bended, the simple bending concrete cover of four-point bending con-crete beam is cut, thus forming a " $\pi$-shaped" notch on the side elevation of the beam. Such beam is called a wide notch concrete beam, which is a new abnormal concrete beam used to study the characteristics of the CRFP plate-concrete interface. With consideration of some theoretical hypotheses, computational analysis and static load test of 4 common concrete beams with EBR CFRP, 4 concrete

${ }^{a}$ Corresponding author : zhhren81@163.com 
beams with wide notch and 3 simple concrete beams (control group), this paper investigated the calculation formula of bending moment-curvature of concrete beam with EBR CFRP and wide notch under different loading phases. The theoretical values of cracking load, yield load, ultimate load and corresponding curvature of the reinforced concrete beam were then calculated. These theoretical values agree well with the test results[10-13,15].

\section{Experiment of concrete beam with EBR CFRP and wide notch}

\subsection{Test materials}

Lica-200 epoxy resin building structure adhesive was used as the testing adhesive. The CFRP plate was $1.4 \mathrm{~mm}$ thick and $50 \mathrm{~mm}$ wide, The bar was measured to have 2504.6 Mpa tensile strength and $1.7 \times 10^{5} \mathrm{Mpa}$ elasticity modulus. The Strength grade of concrete was C30. A total of $11150 \mathrm{~mm} \times 300$ $\mathrm{mm} \times 2600 \mathrm{~mm}$ concrete beams were prepared. In the experiment, the beam span $(l)$ was $2,300 \mathrm{~mm}$ and four-point bending loading was applied. The bottom longitudinal bar used $2 \phi_{14}$, wherese the bearing rod used ${ }_{2} \phi_{8}$. The net concrete cover on the longitudinal bar is $30 \mathrm{~mm}$ thick $(c=30 \mathrm{~mm})$, wherese that on the bearing rod is $25 \mathrm{~mm}$ thick $\left(c^{\prime}=25 \mathrm{~mm}\right)$. To resist shear force, $\phi_{8} @ 150$ stirrup

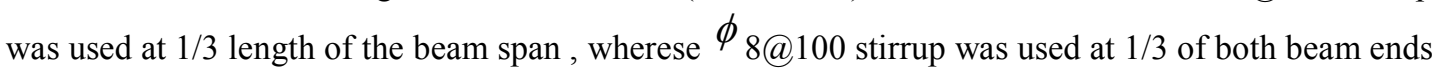
as support[14].

\subsection{Construction of test beam}

The test of the concrete beam with EBR CFRP bar is designed to study the bonding-slip relationship of the CFRP-concrete interface(Fig.1). For the clear force analysis of the CFRP, the middle segment of the beam $\left(l_{0}(600 \mathrm{~mm})\right)$ was emptied into $20 \mathrm{~mm}$. The total length ofthe CFRP is $2100 . l_{1}=750 \mathrm{~mm}$ and the interval between two loading points is not $700 \mathrm{~mm}$. Apparently, $\mathrm{AA}^{\prime} \mathrm{B}^{\prime} \mathrm{B}$ and $\mathrm{DD}^{\prime} \mathrm{C}^{\prime} \mathrm{C}$ apparentlyfall within the simple bending section. The reinforced concrete beam is not influenced by shearing crack at early loading. In other words, additional anti-shearing sections exist at the two ends of the notch to offset the stress concentration at the boundaries.

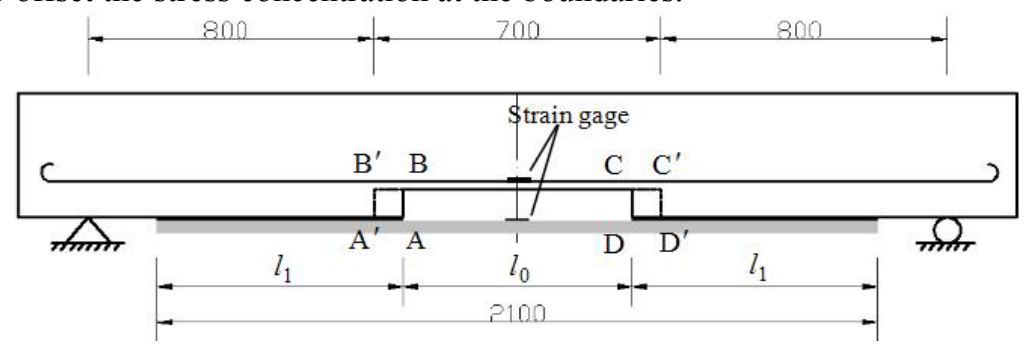

Figure 1. Improved test of EBR CFRP (unit: $\mathrm{mm}$ )

\subsection{Test program and results}

Eleven testing concrete beams, including 3 concrete beams (hereinafter referred as CB), 4 concrete beams using EBR CFRP (hereinafter referred as EBR), and 4 concrete beams with EBR CFRP and wide notch (hereinafter referred as EBRK). Were used. The notch position and test program of EBRK are shown in Fig.1. To export the bonding-slip constitutive relation of CFRP-concrete interface, the author pastes strain gages densely on 11 CFRPs to measure the stress intensity distribution along the length of the CFRP and the relative slippage of the CFRP-concrete interface. 
The static load characteristic values of the 11 tested concrete beams are listed in Table $1 . P_{\text {cr }}$ denotes the cracking load of beams. $P_{\mathrm{y}}$ is the yield load of beams. $P_{\mathrm{u}}$ is the ultimate load of beams. Table 1 shows that EBR receives a better reinforcement effect of CFRP than EBRKCompared with CB, EBR has $28.3 \%, 36.1 \%$ and $35 \%$ higher $P_{\mathrm{cr}}, P_{\mathrm{y}}$ and $P_{\mathrm{u}}$, whereas EBRK has $15 \%, 11.1 \%$ and $17.5 \%$ higher $P_{\mathrm{cr}}, P_{\mathrm{y}}$ and $P_{\mathrm{u}}$. EBR achieves twice the growth of EBRK[14].

Table 1. Significant load value of beams

\begin{tabular}{|c|c|c|c|c|c|c|c|}
\hline $\begin{array}{c}\text { Beam } \\
\text { No. }\end{array}$ & $\begin{array}{c}\text { Pcr/k } \\
\mathrm{N}\end{array}$ & $\begin{array}{c}\text { Pcr } \\
\text { growth }\end{array}$ & Py/kN & $\begin{array}{c}\text { Py } \\
\text { growth }\end{array}$ & $\begin{array}{c}\mathrm{Pu} / \mathrm{k} \\
\mathrm{N}\end{array}$ & $\begin{array}{c}\text { Pu } \\
\text { growth }\end{array}$ & Failure mode \\
\hline CB & 15 & - & 90 & - & 100 & - & Midspan concrete is crushed and bottom breaks \\
\hline EBRK1 & 16 & $6.7 \%$ & 100 & $11.1 \%$ & 130 & $30 \%$ & $\begin{array}{c}\text { Debonding failure of CFRP and brittle failure } \\
\text { covers } \\
\text { the whole beam }\end{array}$ \\
\hline EBRK2 & 18 & $20.0 \%$ & 100 & $11.1 \%$ & 120 & $20 \%$ & $\begin{array}{c}\text { Debonding failure of bottom concrete caused by } \\
\text { CFRP }\end{array}$ \\
\hline EBRK3 & 18 & $20.0 \%$ & 100 & $11.1 \%$ & 110 & $10 \%$ & $\begin{array}{c}\text { Debonding failure of bottom concrete caused by } \\
\text { CFRP }\end{array}$ \\
\hline EBRK4 & 17 & $13.3 \%$ & 100 & $11.1 \%$ & 110 & $10 \%$ & $\begin{array}{c}\text { Debonding failure of bottom concrete caused by } \\
\text { brittle fracture }\end{array}$ \\
\hline EBR1 & 19 & $26.7 \%$ & 100 & $11.1 \%$ & 120 & $20 \%$ & $\begin{array}{c}\text { Tensile failure of CFRP at concrete support. } \\
\text { Concrete } \\
\text { remains uncrushed. }\end{array}$ \\
\hline EBR2 & 20 & $33.3 \%$ & 120 & $33.3 \%$ & 130 & $30 \%$ & $\begin{array}{c}\text { Tensile failure of CFRP at east concrete support. } \\
\text { Concreteremains uncrushed. }\end{array}$ \\
\hline EBR3 & 18 & $20.0 \%$ & 140 & $55.6 \%$ & 150 & $50 \%$ & $\begin{array}{c}\text { Tensile failure of CFRP at east concrete support. } \\
\text { Concreteremains uncrushed. }\end{array}$ \\
\hline EBR4 & 20 & $33.3 \%$ & 130 & $44.4 \%$ & 140 & $40 \%$ & $\begin{array}{c}\text { Tensile failure of CFRP at east concrete } \\
\text { support. Concreteremains uncrushed. }\end{array}$ \\
\hline
\end{tabular}

\section{Bending moment-curvature relationship of EBRK}

\subsection{Basic hypotheses}

The deformation performance of EBRK was studied on the basis of following hypotheses: (1) plane cross-section assumption; (2) relative slippage between CFRP and concrete beam is neglected; (3) concrete stress-strain relationship uses model in the Design Code for Concrete Structures; (4) reinforcing steel bar uses elastic-perfectly plastic material, without consideration of stress strengthening; (5) stress-strain relation of CFRP is linear elasticity; (6) tensile concrete and adhesive layer stand aloof from tension; and (7) effects of shrinkage, creep and temperature stress of concrete and adhesive are neglected.

\subsection{Yield moment $\left(M_{y}\right)$ and yield curvature $\left(\phi_{y}\right)$}

The bending moment-curvature relationship of the EBRK cross section at bending yield can be determined from the geometrical relationship, physical relationship, and condition of static equilibrium.

The stress and strain distributions on the EBRK cross section at bending yield are shown in Fig.2[14].

The bending yield of EBRK includes longitudinal bar yield and CFRP yield. According to the equilibrium of forces[15]: 


$$
\frac{1}{2} b x_{\mathrm{c}} E_{\mathrm{c}} \varepsilon_{\mathrm{c}}+E_{s}^{\prime} \varepsilon_{s}^{\prime} A_{s}^{\prime}=A_{s} E_{s} \varepsilon_{s}+K E_{s} \varepsilon_{s} n_{\mathrm{pf}}^{\prime} A_{\mathrm{pf}}
$$

and

$$
M_{y}=\frac{1}{2} b x_{\mathrm{c}} E_{\mathrm{c}} \varepsilon_{\mathrm{c}}\left(h_{0}-\frac{x_{c}}{3}\right)+A_{\mathrm{s}}^{\prime} E_{s}^{\prime} \varepsilon_{\mathrm{s}}^{\prime}\left(h_{0}-a_{\mathrm{s}}^{\prime}\right)+K E_{s} \varepsilon_{s} n_{\mathrm{pf}}^{\prime} A_{\mathrm{pf}}\left(h_{\mathrm{pf}}-h_{0}\right)
$$

where $h_{0}$ is the distance from the center line of the main reinforcement to the upper edge of concrete; $a_{\mathrm{s}}$ is the distance from the center line of the main reinforcement to the lower edge of concrete; $a_{\mathrm{s}}^{\prime}$ is the distance from the center line of the bearing rod to the upper edge of concrete; $X_{\mathrm{c}}$ is the distance from the neutral axis to the upper edge of concrete; $h^{\prime}$ is the height of the concrete beam (including EBRCFRP), $h^{\prime}=h_{0}+a_{\mathrm{s}}+d_{\mathrm{pf}}\left(d_{\mathrm{pf}}\right.$ is thickness of CFRP); $h$ is the height of the concrete beam,

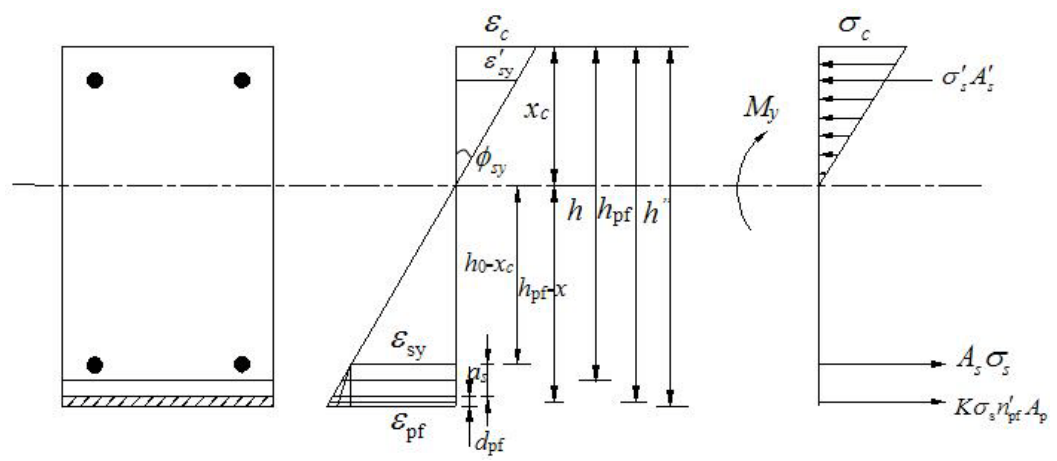

Figure 2. Stress and strain distribution on cross section of EBRK at bending yield

$h=h_{0}+a_{\mathrm{s}} ; E_{\mathrm{s}}$ is the elasticity modulus of tensile reinforcement; $E_{\mathrm{s}}^{\prime}$ is elasticity modulus of compression reinforcement; $E_{\mathrm{c}}$ is the elasticity modulus of concrete; $E_{\mathrm{pf}}$ is the elasticity modulus of $\mathrm{CFRP} ; \varepsilon_{\mathrm{s}}$ is the strain of tensile reinforcement; $\varepsilon_{\mathrm{s}}^{\prime}$ is the strain of compression reinforcement; $\varepsilon_{\mathrm{c}}$ is the strain of concrete; $\varepsilon_{\mathrm{pf}}$ is the strain of CFRP $\left(\varepsilon_{\mathrm{pf}}=K \varepsilon_{\mathrm{s}}=K \varepsilon_{\mathrm{s}}\right) ; K$ is the strain correction coefficient of CFRP $\left(1 \leq K \leq \frac{h^{\prime}-x_{\mathrm{c}}}{h_{0}-x_{\mathrm{c}}}\right) ; h_{\mathrm{pf}}$ is the distance from the section centroid of CFRP to the top beam fiber; $n_{\mathrm{pf}}^{\prime}=E_{\mathrm{pf}} / E_{\mathrm{s}}$ is the elasticity modulus ratio of CFRP and reinforcing steel bar; $A_{\mathrm{pf}}$ is the cross-sectional area of CFRP; $A_{s}$ is the cross-sectional area of the main reinforcement; and $A_{s}^{\prime}$ is the cross-sectional area of the bearing rod.

Given fixed section parameters, $X_{c}$ can be calculated from Equation (1a) after which $M_{y}$ can be calculated from Equation (1b) according to the balance condition of bending moment. At this moment, the yield curvature is: $\phi_{y}=\frac{\varepsilon_{\mathrm{c}}}{x_{\mathrm{c}}}=\frac{\varepsilon_{\mathrm{pf}}}{h_{\mathrm{pf}}-x_{\mathrm{c}}}$. 


\subsection{Ultimate bending moment $\left(M_{\mathrm{u}}\right)$ and ultimate curvature $\left(\phi_{\mathrm{u}}\right)$}

\subsubsection{Definition of failure mode of reinforced beam}

When calculating the ultimate bearing capacity of reinforced members, the failure modes include the following: (1) after tensile reinforcement is yielded, comprehension concrete is destroyed, but CFRP isn't yielded. Such failure mode is the expected ductile failure of EBRK, which occurs upon the appropriate reinforcement ratio of the original beam and CFRP reinforcement. At balanced-reinforcement failure, CFRP is extended fully despite not being broken because the adhesive layer remains undamaged. (2) After tensile reinforcement is yielded, compression concrete isn't destroyed, but CFRP is broken $\left(\varepsilon_{s}=\varepsilon_{y}\right)$. Such failure mode occurs with low reinforcement ratio of the original beam and CFRP reinforcement. The CFRP has reached its ultimate strain ( $\left.\varepsilon_{\mathrm{pf}}=\varepsilon_{\mathrm{pfu}}\right)$, whereas the compression concrete isn't completely developed. Large cracks and deflection can be observed on the beam. (3) Two balanced failures will occur after tensile reinforcement is yielded. Balanced failure I refers to the case in which the : strain of the tensile reinforcement exceeds its yield tensile strain after it is yielded $\left(\varepsilon_{s}>\varepsilon_{y}\right)$ and $\varepsilon_{\mathrm{pf}}$ reaches the ultimate tensile strain $\left(\varepsilon_{\mathrm{pf}}=\varepsilon_{\mathrm{pfu}}\right)$. The compression concrete is crushed, which indicates that $\varepsilon_{c}$ reaches the ultimate compression strain $\left(\varepsilon_{c}=\varepsilon_{c u}\right.$ ). Both reinforcing steel bar and CFRP are brought into full play. Balanced failure $I$ is an ideal critical state that usually dose not occur. In balanced failure II: when the tensile reinforcement is yielded, $\varepsilon_{s}=\varepsilon_{y}$, CFRP is broken $\left(\varepsilon_{\mathrm{pf}}=\left[\varepsilon_{\mathrm{pf}}\right]\right)$ and the compression concrete is destroyed $\left(\varepsilon_{c}=\varepsilon_{c u}\right)$. Balanced failure II is also an ideal critical state that usually dose not occur.

3.3.2 Compression concrete is destroyed, but CFRP is not yielded after the tensile reinforcement is yielded

The stress-strain of the cross section is shown in Fig.3. According to the equilibrium of forces, the ultimate bearingcapacity of the double-reinforcement cross section of EBRK can be calculated.

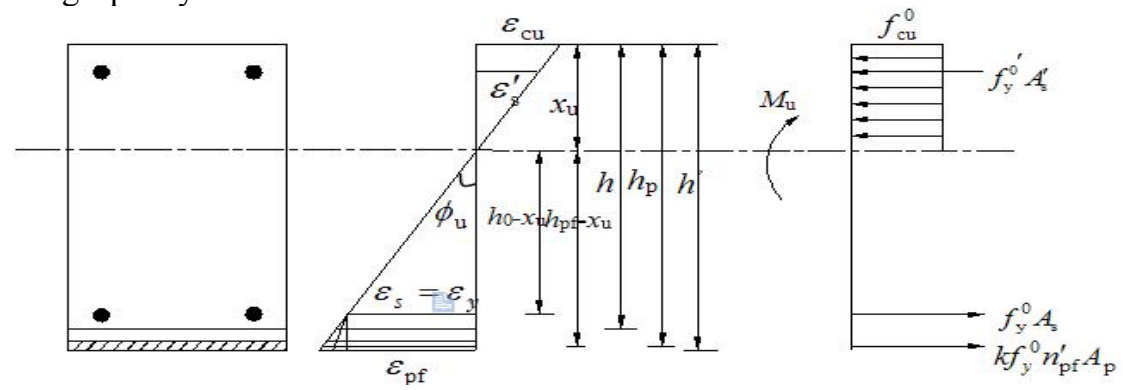

Figure 3. Stress-strain of cross section at ultimate bearing failure

$$
\begin{gathered}
x_{\mathrm{u}}=\frac{A_{\mathrm{s}} E_{s} \varepsilon_{s}+K E_{s} \varepsilon_{s} n_{\mathrm{pf}}^{\prime} A_{\mathrm{pf}}-f_{\mathrm{y}}^{0^{\prime}} E_{s}^{\prime} \varepsilon_{s}^{\prime}}{f_{\mathrm{cu}}^{0} \cdot b} \\
M_{\mathrm{u}} \leq x_{\mathrm{u}} \cdot b \cdot \frac{x_{\mathrm{u}}}{2} f_{\mathrm{cu}}^{0}+A_{s}^{\prime} E_{s}^{\prime} \varepsilon_{s}^{\prime}\left(x_{\mathrm{u}}-a_{\mathrm{s}}^{\prime}\right)+A_{\mathrm{s}} E_{s} \varepsilon_{\mathrm{sy}}\left(h_{0}-x_{\mathrm{u}}\right)+K E_{s} \varepsilon_{s} n_{\mathrm{pf}}^{\prime} A_{\mathrm{pf}}\left(h_{\mathrm{pf}}-x_{\mathrm{u}}\right)
\end{gathered}
$$

where $f_{\mathrm{cu}}^{0}$ is the compressive strength of concrete. Therefore, the curvature of the cross section is. 


$$
\phi_{\mathrm{u}}=\frac{\varepsilon_{\mathrm{cu}}}{X_{\mathrm{u}}}=\frac{\varepsilon_{\mathrm{pf}}}{h_{\mathrm{pf}}-x_{\mathrm{u}}}
$$

In Equations (2a) and (2b), the strain of CFRP uses the measured strain of its outermost fiber $\left(h_{\mathrm{pf}}=h^{\prime}\right)$. Given that the vertical stress or strain distribution of CFRP is uneven, the train at the stress center of the CFRP cross section ( $\varepsilon_{\mathrm{px}}$ ) shall be used for accurate computation (Fig.4). In Fig.4, $h_{1}$ is the distance from the cut simple bending bottom to the upper edge of the beam.

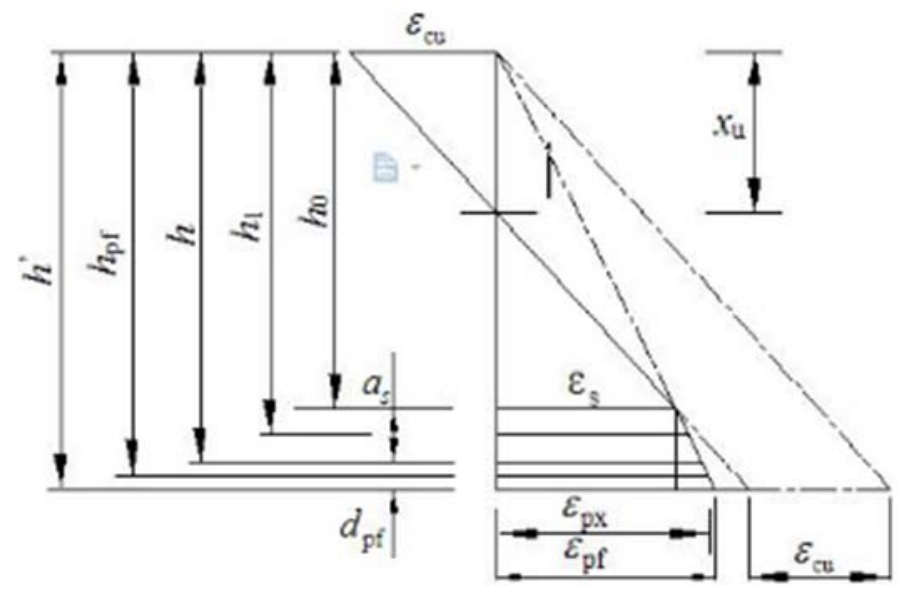

Figure 4. Calculation of $\varepsilon_{\mathrm{px}}$

Given that $\varepsilon_{\mathrm{s}} \leq \varepsilon_{\mathrm{px}} \leq \varepsilon_{\mathrm{pf}}$ and $\varepsilon_{\mathrm{pf}}=K \varepsilon_{\mathrm{s}}$, according to geometric similarity, we determine that,

$$
\frac{\varepsilon_{\mathrm{pf}}-\varepsilon_{\mathrm{s}}}{a_{\mathrm{s}}+d_{\mathrm{pf}}}=\frac{\varepsilon_{\mathrm{px}}-\varepsilon_{\mathrm{s}}}{a_{\mathrm{s}}+\frac{3 a_{\mathrm{s}}+2 d_{\mathrm{pf}}}{6 a_{\mathrm{s}}+3 d_{\mathrm{pf}}} d_{\mathrm{pf}}}
$$

Then,

$$
\varepsilon_{\mathrm{px}}=\left[1+\frac{(K-1)\left(a_{\mathrm{s}}+\frac{3 a_{\mathrm{s}}+2 d_{\mathrm{pf}}}{6 a_{\mathrm{s}}+3 d_{\mathrm{pf}}} d_{\mathrm{pf}}\right)}{a_{\mathrm{s}}+d_{\mathrm{pf}}}\right] \varepsilon_{\mathrm{s}}
$$

When calculating the ultimate bearing capacity of the EBRK cross section,

$$
\sigma_{\mathrm{pf}}=\left[1+\frac{(K-1)\left(a_{\mathrm{s}}+\frac{3 a_{\mathrm{s}}+2 d_{\mathrm{pf}}}{6 a_{\mathrm{s}}+3 d_{\mathrm{pf}}} d_{\mathrm{pf}}\right)}{a_{\mathrm{s}}+d_{\mathrm{pf}}}\right] n_{\mathrm{pf}}^{\prime} f_{\mathrm{s}}^{0}
$$

3.3.3 CFRP is broken but compression concrete is not damaged after the tensile reinforcement is yielded

In Fig.3, the ultimate bearing capacity of the double-reinforcement cross section of EBRK can be calculated according to the equilibrium of forces: 


$$
\begin{gathered}
M_{\mathrm{u}} \leq x_{\mathrm{c}} \cdot b \cdot \frac{x_{\mathrm{c}}}{2} \sigma_{\mathrm{c}}+A_{\mathrm{s}}^{\prime} f_{\mathrm{y}}^{0^{\prime}}\left(x_{\mathrm{c}}-a_{\mathrm{s}}^{\prime}\right)+A_{\mathrm{s}} f_{\mathrm{y}}^{0}\left(h_{0}-x_{\mathrm{c}}\right)+f_{\mathrm{pfu}} A_{\mathrm{pf}}\left(h_{\mathrm{pf}}-x_{\mathrm{c}}\right) \\
x_{\mathrm{u}}=\frac{A_{\mathrm{s}} f_{\mathrm{y}}^{0}+f_{\mathrm{pfu}} A_{\mathrm{pf}}-f_{\mathrm{y}}^{0^{\prime}} A_{\mathrm{s}}^{\prime}}{\sigma_{c} \cdot b}
\end{gathered}
$$

where $f_{\mathrm{y}}^{0^{\prime}}$ is the compressive strength of the bearing rod; $f_{\mathrm{y}}^{0}$ is the tensile strength of the main rein- forcement; and $f_{\mathrm{pfu}}$ is breaking strength of CFRP. Therefore, the curvature of the cross section is

$$
\phi_{\mathrm{u}}=\frac{\varepsilon_{\mathrm{s}}}{h_{0}-x_{\mathrm{c}}}=\frac{\varepsilon_{\mathrm{pfu}}}{h_{\mathrm{pf}}-x_{\mathrm{c}}}
$$

\subsubsection{Balanced failure}

In Fig.3, balanced failure I can be calculated from the deformation compatibility conditions:

$$
x_{\mathrm{u}}=\frac{\varepsilon_{\mathrm{cu}}\left(h_{\mathrm{pf}}-\frac{1}{2} d_{\mathrm{pf}}\right)}{\varepsilon_{\mathrm{pfu}}+\varepsilon_{\mathrm{cu}}}
$$

Therefore, the curvature of the cross section is

$$
\phi=\frac{\varepsilon_{\mathrm{cu}}}{x_{\mathrm{u}}}=\frac{\varepsilon_{\mathrm{pfu}}}{h_{\mathrm{pf}}-x_{\mathrm{u}}}
$$

In Fig.3, balanced failure II can be calculated from the deformation compatibility conditions:

$$
x_{\mathrm{u}}=\frac{\varepsilon_{\mathrm{cu}}\left(h_{\mathrm{pf}}-\frac{1}{2} d_{\mathrm{pf}}\right)}{\varepsilon_{\mathrm{cu}}+\left[\varepsilon_{\mathrm{pf}}\right]}
$$

Therefore, the curvature of the cross section is

$$
\phi=\frac{\varepsilon_{\mathrm{cu}}}{x_{\mathrm{u}}}=\frac{\left[\varepsilon_{\mathrm{pf}}\right]}{h_{\mathrm{pf}}-x_{\mathrm{u}}}
$$

\section{Test results of bending moment-curvature relationship}

$\phi_{\mathrm{y}}$ and $\phi_{\mathrm{u}}$ as well as the corresponding $\mu_{\varphi}$ (Table 2) can be derived from the above curvature formulas. The $M-\phi$ charts of beams can be drawn (Fgi.5). In Table 2, $\phi_{\mathrm{yt}}$ and $\phi_{\mathrm{yc}}$ are the test and theoretical value of yield curvature, respectively; $\phi_{\mathrm{ut}}$ and $\phi_{\mathrm{uc}}$ are the test and theoretical values of ultimate curvature, respectively; $\mu_{\varphi t}$ and $\mu_{\varphi c}$ are the test and theoretical value of the ductility factor of sectional curvature, respectively; and $P_{\mathrm{y}}$ and $P_{\mathrm{u}}$ are yield load and ultimate load, respectively. In Table 2, $\mu_{\varphi t} / \mu_{\varphi c}$ of CB is 1.07. The $\mu_{\varphi t} / \mu_{\varphi c}$ of EBRK are 1.08, 0.98, 0.97 and 0.98. The $\mu_{\varphi t} / \mu_{\varphi c}$ values of EBR are $0.96,0.98,0.98$ and 0.99 , all of which are smaller than those of CB. This finding- 
indicates that although CFRP can increase the cracking, yield and ultimate loads of both EBRK and EBR, CFRP decreases their ductility to a certain extent. However, the $\mu_{\varphi t} / \mu_{\varphi c}$ values of both EBRK and EBR are within the acceptable range, indicating that both EBRK and EBR can satisfy the ductility requirement. Moreover, the ductility factors of EBRK are smaller than those of EBR, indicating that the rigidity of EBRK is higher than that of EBR.

Table 2. Ductility factor of sectional curvature of testing beams

\begin{tabular}{|c|c|c|c|c|c|c|c|c|c|c|}
\hline \multirow{2}{*}{$\begin{array}{l}\text { Beam } \\
\text { No. }\end{array}$} & \multirow{2}{*}{$P_{\mathrm{y}} / \mathrm{kN}$} & \multirow{2}{*}{$P_{\mathrm{u}} / \mathrm{kN}$} & \multirow{2}{*}{$P_{\mathrm{u}} / P_{\mathrm{y}}$} & \multicolumn{2}{|c|}{$\begin{array}{c}\text { Yield curvature } \\
\left(10^{-5} \mathrm{~mm}\right)\end{array}$} & \multicolumn{2}{|c|}{$\begin{array}{c}\text { Ultimate curvature } \\
\left(10^{-5} \mathrm{~mm}\right)\end{array}$} & \multirow{2}{*}{$\mu_{\varphi t}$} & \multirow{2}{*}{$\mu_{\varphi c}$} & \multirow{2}{*}{$\begin{array}{l}\mu_{\varphi t} \\
\mu_{\varphi c}\end{array}$} \\
\hline & & & & $\phi_{\mathrm{yt}}$ & $\phi_{\mathrm{yc}}$ & $\phi_{\mathrm{ut}}$ & $\phi_{\mathrm{uc}}$ & & & \\
\hline $\mathrm{CB}$ & 90 & 100 & 1.11 & 6.01 & 6.91 & 13.56 & 14.36 & 2.26 & 2.08 & 1.07 \\
\hline EBRK1 & 100 & 130 & 1.30 & 3.98 & 4.19 & 8.49 & 8.31 & 2.13 & 1.98 & 1.08 \\
\hline EBRK2 & 100 & 120 & 1.20 & 4.60 & 4.39 & 9.41 & 9.22 & 2.05 & 2.10 & 0.98 \\
\hline EBRK3 & 100 & 110 & 1.10 & 4.21 & 4.01 & 8.76 & 8.58 & 2.08 & 2.14 & 0.97 \\
\hline EBRK4 & 100 & 110 & 1.10 & 4.92 & 4.73 & 9.48 & 9.31 & 1.93 & 1.97 & 0.98 \\
\hline EBR1 & 100 & 120 & 1.20 & 4.02 & 3.82 & 8.45 & 8.31 & 2.10 & 2.18 & 0.96 \\
\hline EBR2 & 12 & 130 & 1.10 & 5.57 & 5.36 & 11.85 & 11.7 & 2.13 & 2.18 & 0.98 \\
\hline EBR3 & 140 & 150 & 1.10 & 6.49 & 6.31 & 13.69 & 13.56 & 2.11 & 2.15 & 0.98 \\
\hline EBR4 & 130 & 140 & 1.10 & 6.18 & 5.99 & 12.24 & 12.10 & 2.00 & 2.02 & 0.99 \\
\hline
\end{tabular}

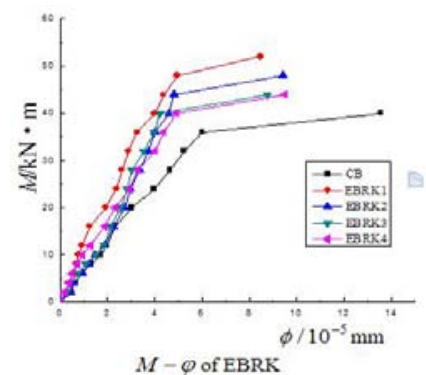

(a)

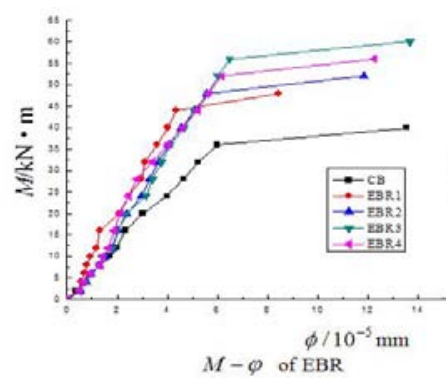

(b)

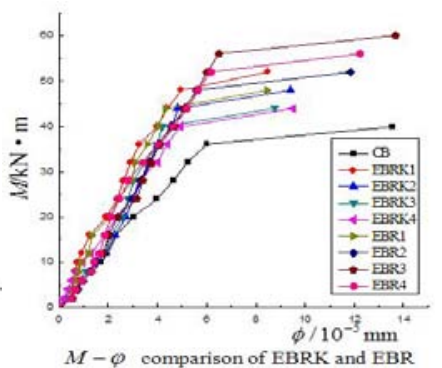

(c)

Figure 5. $M-\varphi$ of testing beams

\section{Conclusions}

On the basis of the force analysis of $3 \mathrm{CB}, 4$ EBRK and 4 EBR under the cracking, yield and ultimate phases, we can conclude that:

(1) Compared with EBR, EBRK presents clearer forces on CFRP. This condition is convenient for the strain test and force analysis of CFRP. EBRK is superior for use in studying the bonding slippage and macroscopic bearing capacity of CFRP-concrete interface.

(2) CFRP can improve the deformation resistance of EBRK and EBR to a certain extent. EBRK shows smaller deformation than EBR.

(3) A formula for calculating the bending moment-curvature of EBRK and EBR under different stress phases is proposed. The calculated results agree well with the test results, indicating that the derived formulas and calculation method are feasible. This approach can provide theoretical references for engineering designers for practical engineering applications.

\section{Acknowledgement}

This work was financially supported by The National Natural Science Foundation of China(51678430), China Postdoctoral Science Foundation(2016M591707), The Science and Research 
Program of Hunan Province(2015SK20543), key scientific research project of Education Commission of Hunan Province (16A050), Doctoral Science Foundation of Hunan Institute of Engineering.

\section{References}

1. WangTong, Wang Zong-lin, Zhang Shu-ren, Chen Shu-xian, China. China Journal of Highway and Transport, vol.15(2),61-67, (2002)

2. ZhangKe,Yue Rui-qing,Fu Chang-wu,et al, China.Journal of industrial Construction, vol.31(6), 20-23, (2002)

3. Nanni A, Matta F, Galati N, USA.Report CAE 06-01. Miami, FL: Department of Civil, Architectural and Environmental Engineering, University of Miami, (2006)

4. Liu I S T, Oehlers D J, Seracino R, USA. Journal of Composites for Construction, vol.10(2), 106$114,(2006)$

5. Oehlers D J, USA.Cement and Concrete Composites, vol. 28(10),898-905, (2006)

6. Wight R G, Green M F, Erki M-A (2001), USA. Journal of Composites for Construction, vol.5(4), 214-220, (2001)

7. Sima yuzhou,Zhu hongping, China.Zhang jianwen Journal of Huazhong University of Science and Technology (Urban Science Edition), vol.25(3), 226-229,(2008 )

8. Zoghi M, SAMPE Journal, vol.42(2), 24-30, (2006)

9. Ding yahong, Liu lina.China.Journal of Engineering Mechanics, vol.30(4),191-197,( 2013)

10. Zeng Xiantao, Cheng Xiangli, Gao Baobin, China.Engineering Mechanics, vol.25(12), 106-113, (2008)

11. Wang yaoyan, Zhou hongwen,China.Journal of Railway Engineering, vol.12,10-12, (2008)

12. Wu Bo,Wang Wei-jun, Wang Fan,China.Journal of South China University of Technology ( Natural Science Edition ), vol.33(1), 10-15, (2005)

13. Zang Bo, Zhu Dong-sheng et al, China. Journal Of Chongqing Jiaotong University (Natural Science), vol.30(1), 13-18, (2011)

14. Ren Zhenhua, Zeng Xiantao, China.Journal of Natural Disasters, (3), 221-228, (2013)

15. Ren Zhenhua. China.Ph. D. thesis.Hohai University, Nanjing,China. December 4,(2012) 